\title{
Types of Diagenetic Facies of Tight Sandstone Reservoir and Its Quantitative Identification by Well Log Data
}

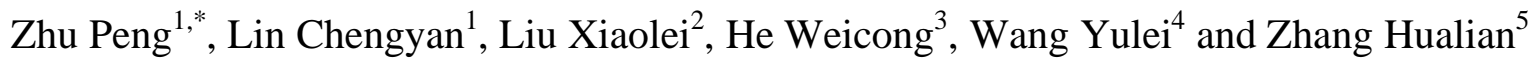

${ }^{1}$ School of Geosciences in China University of Petroleum, Qingdao 266580, China; ${ }^{2}$ Sinopec Shengli Oil Field Zhuangxi Researching Center, Dongying 257000, China; ${ }^{3}$ BGP Company, CNPC, Zhuozhou 072751, China; ${ }^{4}$ Sinopec Shengli Oil Field Drilling Technology Research Institute, Dongying 257000, China; ${ }^{5}$ Chongqing Institute of Geology \& Mineral Resources, Chongqing, 400042, China

\begin{abstract}
According to the features of clastic mineral components, diagenesis, diagenetic mineral combination, etc., the tight sandstone reservoir of $\mathrm{Es}_{3} \mathrm{x}^{1}$ in block Zhuang62-66 is classified into 5 types of diagenetic facies by the analysis of thin sections, casting thin sections, scanning electron microscopy and core description. Natural gamma (GR), true formation resistivity (Rt), flushed zone formation resistivity (Rxo), compensated neutron (CNL), density (DEN), acoustic (AC) and spontaneous potential (SP) are selected on the basis of comprehensively analyzing the log response mechanism of different diagenesis. The effective log recognition model of diagenetic facies is established on the basis of principal component analysis, five comprehensive variables $F_{1} \sim F_{5}$ are built, while $F_{1}$ and $F_{2}$ account for $91.4 \%$ of the total variance, which could replace primitive multi-dimension information. The method is verified through processing of coring wells, thus providing a geological basis for the high quality reservoir prediction of the oilfield in the future.
\end{abstract}

Keywords: Diagenetic facies, diagenesis, quantitative identification by well log data, principal component analysis.

\section{INTRODUCTION}

Tight sandstone reservoirs often experience complex diagenesis, especially those which are adverse to pore preservation, such as compaction, cementation, etc. As a comprehensive performance of reflecting diagenetic products of specific diagenetic environments or processes, diagenetic facies obviously controls petrophysical properties of reservoirs [1-5]. Diagenetic facies analysis is to establish a genetic relationship between diagenesis and the evolution characteristics of reservoir petrophysical properties, and to clarify the combination types and distribution characteristics of diagenetic facies, and their effect on petrophysical properties of reservoirs, thus providing the theoretical basis for summarizing the characteristics of development of reservoirs in transverse and longitudinal sections [6-14]. In recent years, through studies on diagenetic facies, many experts and scholars suggested that, as a key controlling factor of the development of high quality reservoirs, distribution of diagenetic facies is a vital guidance for the exploration of "dessert" reservoirs against the background of low permeability-tight reservoirs especially $[15,16]$.

Currently, diagenetic facies research mainly relies on the data of cores and thin sections from coring wells, while drilling cores can not be applied to the continuous division of diagenetic facies due to high cost and its limited number. As wirelone logging can provide a lot of information about petrophysical properties, logging data has unique advantages in terms of data quality, resolution, continuity, economic

\footnotetext{
*Address correspondence to this author at the School of Geosciences in China University of Petroleum, Qingdao 266580, China;

Tel: +86053286983103; E-mail: pursuit_joe@163.com
}

cost, etc. A lot of research of utilizing log information to classify reservoir diagenetic facies has been done [16-20]. The key is to summarize the log response characteristics of different diagenetic facies with the guidance of logging geology and other related disciplines and to establish the corresponding model and criterion of log recognition based on the mathematical statistics, finishing the recognition of types of diagenetic facies except for coring intervals. On the basis of previous studies, the author took tight sandstone reservoir of $\mathrm{Es}_{3} \mathrm{x}^{1}$ in block Zhuang 62-66 as an example. On the basis of research on the characteristics of diagenetic facies, effective $\log$ discrimination standard of diagenetic facies is established based on the principal component analysis. Qualification rate of correction of core samples is over $85 \%$, providing a geological basis for exploration and development of the oilfield in the next step.

\section{CHARACTERISTICS OF DIAGENESIS AND DI- AGENETIC FACIES}

\subsection{Analysis of Diagenesis and its Log Response Mecha-} nism

\subsubsection{Compaction}

The content of cuttings, matrix and other plastic grains of reservoir of $\mathrm{Es}_{3} \mathrm{x}^{1}$ in block Zhuang62-66 is so high that the formation has poor anti-pressure ability. Pores are easily destroyed due to compaction. Common compaction phenomena (Fig. (1a), Fig. (1b)) include: linear-concave convex contact of clastic particles; compressional deformation, distortion and pseudomatrixization of mudstones, shale cuttings, shale matrix, micas and other plastic grains; wavy extinction or even crushed or fractured of quartzs, feldspars 

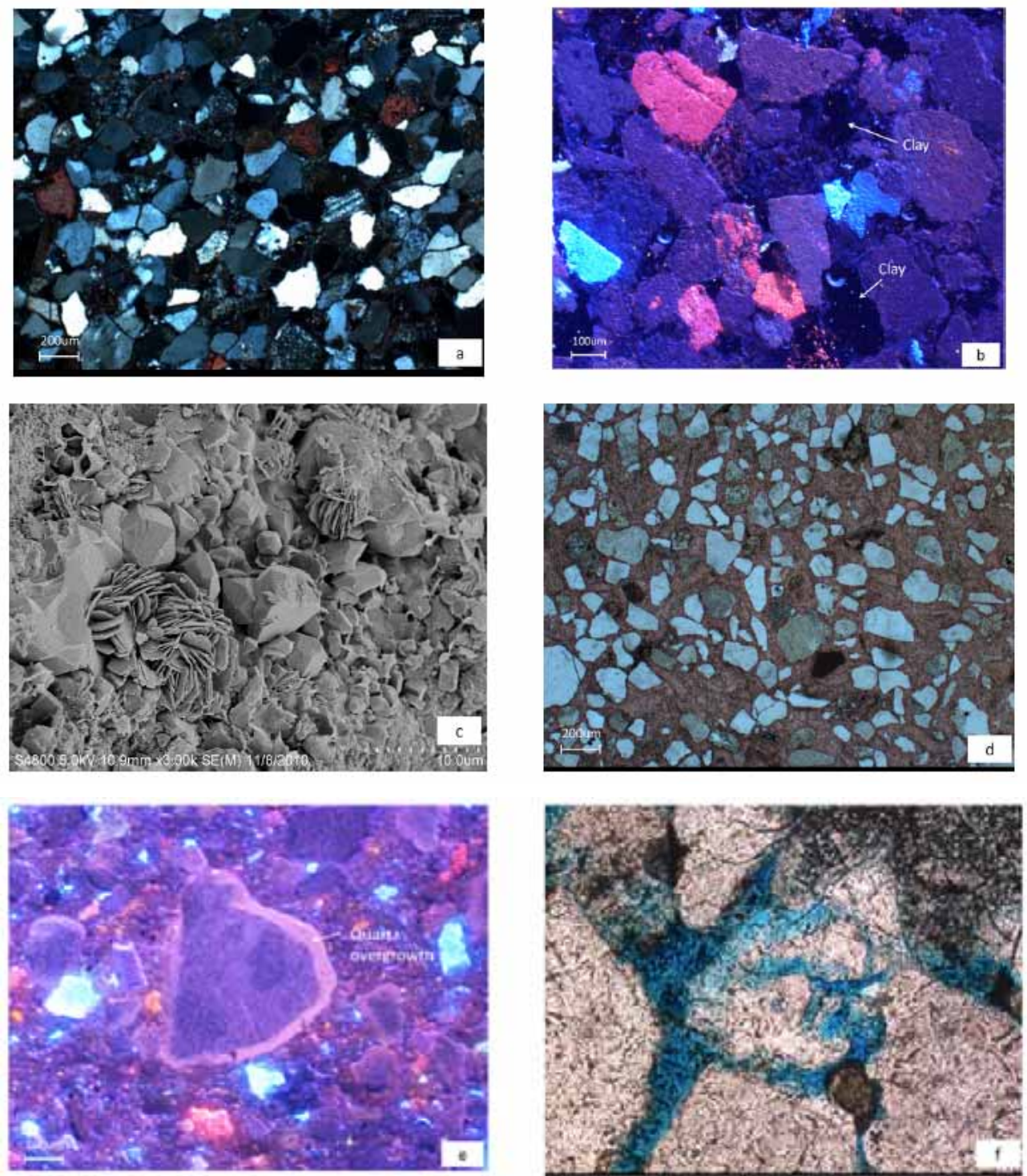

Fig. (1). Micro-image characteristics of tight sandstone reservoir of $\operatorname{Es}_{3} x^{1}$ in block Zhuang 62-66 in Wuhaozhuang Oilfield. (a) Zhuang62, 3108.63m relatively uniform in particle distribution, intensive compaction, fractured rigid particles and directionally arranged plastic grains, intergranularly interstitial material is mainly sheet clay matrix(orthogonal light); (b) Zhuang66-1, 3452.45m clay mineral is mainly intergranularly interstitial material with a content of 5\%-25\% generally, according to x-ray diffraction, the main component is kaolinite, illite and chlorite, mixed-layer clay minerals (cathode luminescence); (c) Zhuang62, 3128.69m booklet kaolinite filling of intergranular pores(scanning electron microscope); (d) Zhuang 66-1, 3404.7m mainly fine sand, the main component is quartz, feldspar and volcanic debris, lots of crystal granular calcite filling of base cementation(orthogonal light); (e) Zhuang66-12-12, 3198.4m irregular quartz overgrowth, quartz edge is $0.03-0.06 \mathrm{~mm}$, mosaic contact between quartz grains(cathode luminescence); (f) Zhuang66-1, 3448.75m zigzag and wreck edge dissolution of feldspar grains(plane-polarized light).

and other rigid particles. In general, compaction leads to lower value of AC, higher value of $\mathrm{DEN}$, lower value of CNL, and smaller magnitude difference of SP.

\subsubsection{Cementation}

Cementation of reservoir of $\mathrm{Es}_{3} \mathrm{x}^{1}$ in block Zhuang 62-66 is mainly clay mineral cementation, carbonate cementation and siliceous cementation. Cementation is mainly authigenic clay mineral cementation, followed by carbonate cementation and then siliceous cementation. In general, cementation leads to overall deterioration of petrophysical properties, while different types of cementation have different log response mechanisms.
Clay mineral cementation is mainly kaolinite cementation, followed by illite and illite/smectite mixed layer cementation (Table 1). Authigenic clay minerals filling of intergranular pores leads to complicated reservoir pore structure (Fig. (1c)). Film-like or pore-lining produced clay minerals result in clogged pore throats, greatly reducing the effective porosity of reservoirs. Clay mineral cementation generally results in GR increasing, AC increasing, Rt decreasing and DEN increasing.

It is rich in carbonate cements and has multiple types, indicating obvious characteristics of multiple stages. According to the generation, cementation and interpenetration 
Table 1. Content of clay minerals of tight sandstone reservoir of $\mathrm{Es}_{3} \mathrm{x}^{1}$ in block Zhuang 62-66.

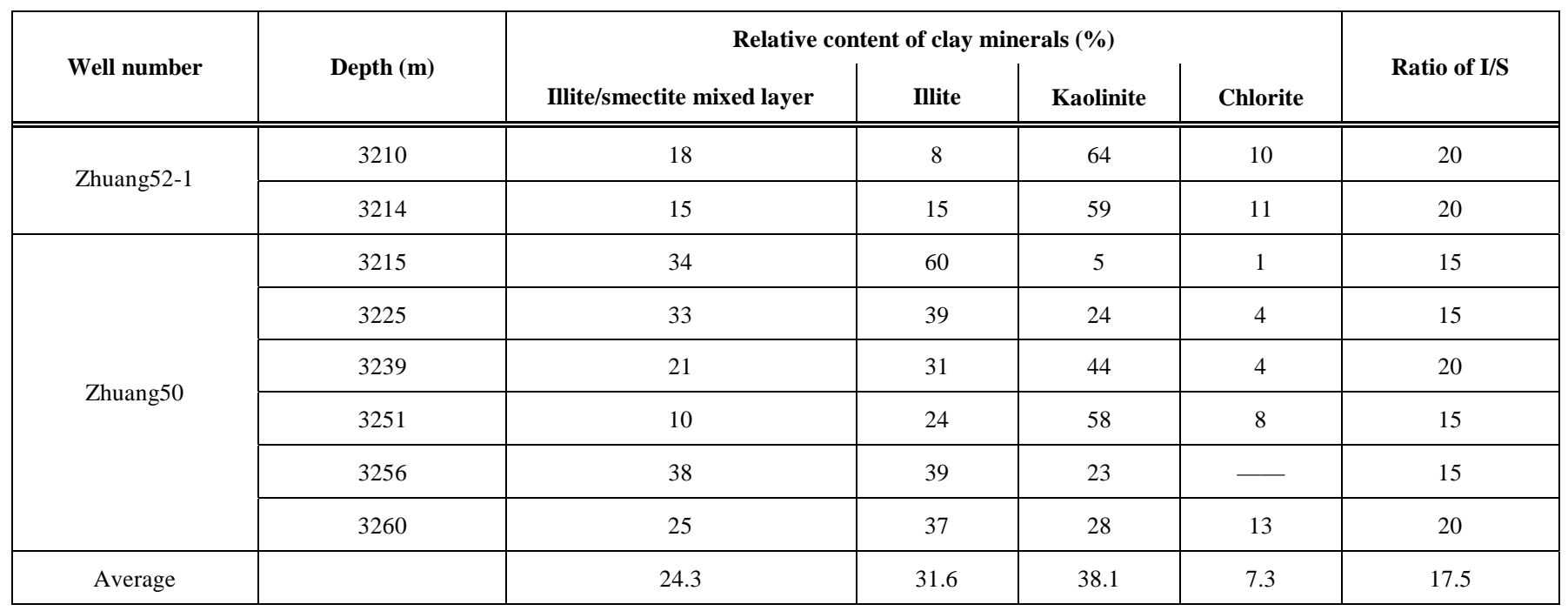

relationship of authigenic minerals, cementation types include calcite, dolomite and other early cementation and ferrocalcite, ferrodolomite and other late cementation. Early and late period of cements have different features and effects on petrophysical properties (Fig. (1d)). Carbonate cementation is the most important factor leading to tight reservoirs which are generally characterized by low value of AC, high value of DEN, low value of CNL, medium-high value of Rt, low value of GR.

It is relatively low in siliceous cements. The most common siliceous cementation is quartz overgrowth and authigenic quartz grain filling pores (Fig. (1e)), which are mainly produced by pressure solution and silicon released in transformation from feldspar to kaolinite. Siliceous cementation results in contact forms from point contact to suture line and surface contact, resulting in deterioration of reservoir petrophysical properties and shortened acoustic propagation path, so AC cannot fully reflect intergranular pores [17]. The reservoirs are generally characterized by AC decreasing, DEN increasing, Rt increasing.

\subsubsection{Dissolution}

Dissolution is a key factor in the development of secondary pores and it improves reservoir petrophysical properties. Dissolution of unstable components increases rock maturity (Fig. (1f)) and improves reservoir petrophysical properties as well. Reservoirs with development of dissolution are characterized by medium-high value of $\mathrm{AC}$, low value of DEN, high value of CNL and low value of GR.

\subsection{Classification and Characteristics of Diagenetic Fa- cies}

Based on the data of thin sections, casting thin sections, scanning electron microscopy, etc. and the comprehensive consideration of effect of diagenesis on petrophysical properties, combining with the analytical data of conventional petrophysical properties, reservoir of $\mathrm{Es}_{3} \mathrm{x}^{1}$ in block Zhuang 62-66 is divided into 5 kinds of diagenetic facies and the characteristics of each diagenetic facies are summarized as follows.

\subsubsection{Compaction-matrix Filling and Tightness}

Lithology of this diagenetic facies is relatively fine. Contents of mudstones and shale cuttings, clay matrix, micas, phyllites, slates, etc. are relatively high. The soft component is strongly deformed during compaction, leading to a sharp decrease of primary pores. Quartz overgrowth resulted from the pressure solution of late rigid particles and the filling of authigenic clay minerals and calcareous cements further reduce reservoir porosity. Reservoir pores are mainly compaction residual intergranular pores, a few dissolution pores and intercrystalline micropores. Reservoir petrophysical properties are poor. Porosity is $2.4 \% \sim 9.8 \%$, and permeability is 0.1 $\sim 2.3 \mathrm{mD}$.

\subsubsection{Authigenic Clay Minerals Filling and Cementation}

According to X-ray diffraction data (Table 1), authigenic clay mineral of $\mathrm{Es}_{3} \mathrm{X}^{1}$ in block Zhuang 62-66 is mainly kaolinite, followed by illite and illite/smectite mixed layer, content of chlorite is relatively low. The average content of kaolinite is $38.1 \%$, which fills pores in the form of vermicular and booklet aggregate. Although it provides some intergranular pores, its growth fills pore throats and formed tiny intergranular pores leads to the invalid pores increases and poorer permeability; the average content of illite is $31.6 \%$ which generally exists on particle surface or fills in pores, occupying pore space and clogging throats. Reservoir pores are mainly residual intergranular pores and intercrystalline micropores. Reservoir petrophysical properties are poor. Porosity is $4.9 \% \sim 13.6 \%$, and permeability is $0.15 \mathrm{mD} \sim$ 20.6mD.

\subsubsection{Unstable Components Dissolution}

According to the analysis of thin sections, dissolution of $\mathrm{Es}_{3} \mathrm{X}^{1}$ in block Zhuang 62-66 mainly occurs in feldspars, cutting grains, carbonate cements and clay matrix. Reservoir space of unstable components dissolution diagenetic facies includes: a certain number of dissolved pores sticking grains produced by the dissolution of clay cladding formed on the edges of mineral grains in early diagenesis stage; lots of honeycomb or irregular intragranular dissolved pores formed by corrosion of underground fluid along the fracture plane of 
the cleavage surface of feldspar; intragranular dissolved pores of dentate edges formed by corrosion of edges of grains. Reservoir petrophysical properties are the best. Porosity is $9.1 \% \sim 23.2 \%$, and permeability is $3.5 \mathrm{mD} \sim 31.2 \mathrm{mD}$.

\subsubsection{Quartz Overgrowth}

Siliceous cementation is relatively common in $\mathrm{Es}_{3} \mathrm{x}^{1}$ reservoir with a relatively low content, the average content of siliceous cement is about 2\%. Quartz overgrowth often occurs in clastic reservoirs with fewer matrixes and better sorting, and often accompanied by corrosion of feldspar. Chemical changes occur in feldspar under the appropriate $\mathrm{PH}$ value (acid medium provided by organic acids) and generates kaolinite and $\mathrm{K}^{+}, \mathrm{Al}^{3+}$ and $\mathrm{SiO}_{2}$ as well. This reaction provides certain material sources for quartz overgrowth $\left(\mathrm{SiO}_{2}\right)$. Quartz overgrowth fills in intergranular pores and changes reservoir pore structure, resulting in deterioration of reservoir petrophysical properties. Porosity is $7.1 \% \sim 15.8 \%$, and permeability is $0.64 \mathrm{mD} \sim 10.6 \mathrm{mD}$.

\subsubsection{Carbonate Cementation and Tightness}

According to the degree of cementation, ferrocalcite cementation, with mostly microcrystalline-fine crystalline structure, is divided into complete filling and partial filling. Ferroan calcite, ferruginous dolomite and other late carbonate cements are mostly semi-crystalline or filling cementation whose obvious plugging pore effect shows that the diagenetic environment gradually evolves to the alkaline environment due to the continuous consumption of acidic fluids. A large amount of ferroan calcites, ferruginous dolomite and other iron-bearing carbonates generated in the process decreases the reservoir petrophysical properties [21]. Reservoir petrophysical properties are the worst with only a few compaction residual intergranular pores and intercrystalline micropores. Porosity is $1.8 \% \sim 7.3 \%$, and permeability is $0.04 \mathrm{mD} 2.55 \mathrm{mD}$.

\section{QUANTITATIVE LOG RECOGNITION OF DI- AGENETIC FACIES BASED ON PRINCIPAL COM- PONENT ANALYSIS}

\subsection{Principle of Principal Component Analysis}

High-dimensional arrays are often encountered in data processing. It is difficult to grasp the main information due to high dimensions, multi variables and correlation among variables. In order to analyze these multivariate data, dimensionality must be reduced properly [22-24]. Principal component analysis is a method of data dimensionality reduction, which reflects the hidden structure of the best explanatory variables of the data to a certain extent. Using the projection method to project the high-dimensional data onto lowdimensional space with the least possible loss of information, the aim of simplifying data structures from data dimension reduction is achieved.

The basic idea of principal component analysis is as follows. Set P-dimensional random vector $X=\left(x_{1}, x_{2} \cdots x_{p}\right)^{T}$. Its mean vector is $u$ and covariance matrix is $V$. Reconstitute the feature vectors $x_{1}, x_{2} \cdots x_{p}$ into several unrelated variables $y_{1}, y_{2} \cdots y_{m}(m<p)$ as little as possible and make sure they can fully reflect information reflected by the original $\mathrm{P}$ feature vectors.
Steps to get the n-dimensional observation sample matrix $\mathrm{X}$ of the $\mathrm{P}$ feature vectors are as follows.

$$
X=\left[\begin{array}{ccccc}
x_{11} & & x_{12} & & x_{1 p} \\
& & & \cdots & \\
x_{21} & & x_{22} & & x_{2 p} \\
& \vdots & & \ddots & \vdots \\
x_{n 1} & & x_{n 2} & \cdots & x_{n p}
\end{array}\right]
$$

(1) Normalization of the raw data, i.e. the sample concentrated element $x_{i k}$ is converted as follows:

$$
\begin{aligned}
& x_{i k}=\frac{x_{i k}-\bar{x}_{k}}{S_{k}^{2}}(i=1,2, \ldots . n ; k=1,2, \ldots . p) \\
& \bar{x}_{k}=\frac{1}{n} \sum_{i=1}^{n} x_{i k} \\
& S_{k}^{2}=\frac{1}{n-1} \sum_{i=1}^{n}\left(x_{i k}-\bar{x}_{k}\right)^{2}
\end{aligned}
$$

The obvious feature of principal component analysis is that every principal component depends on the scale of original variables measurement. When the scale varies, the eigenvalue $\lambda$ is different. To overcome this difficulty, original variables are normalized as mentioned above to make the variance 1 .

(2) Calculate the correlation coefficient matrix of the sample matrix:

$$
R=\left[\begin{array}{ccccc}
r_{11} & & r_{12} & & r_{1 p} \\
& & & \cdots & \\
r_{21} & & r_{22} & & r_{2 p} \\
& \vdots & & \ddots & \vdots \\
r_{n 1} & & r_{n 2} & \cdots & r_{n p}
\end{array}\right]
$$

(3) Corresponding to the correlation coefficient matrix $R$, get $P$ non-negative eigenvalues $\left(\lambda_{1}>\lambda_{2}>\cdots>\lambda_{p} \geq 0\right)$ of the equation $|R-\lambda I|=0$ with the Jacobi method. The corresponding feature vectors of the eigenvalue $\lambda_{i}$ are as follows:

$C^{(i)}=\left(C_{1}^{(i)}, C_{2}^{(i)}, \cdots C_{p}^{(i)}\right)$

And meet:

$$
C^{(i)} C^{(j)}=\sum_{k=1}^{p} C_{k}^{(i)} C_{k}^{(j)}= \begin{cases}1 & (i=j) \\ 0 & (i \neq j)\end{cases}
$$

(4) Select $m(m<p)$ principal components. When a

$\left(a=\left(\sum_{i=1}^{m} \lambda_{i}\right) /\left(\sum_{i=1}^{p} \lambda_{i}\right)\right)$

$(\mathrm{m}<\mathrm{P})$ is close to 1 (for example $a \geq 0.9$ ), choose factors $y_{1}, y_{2} \cdots y_{m}$ as the principal components corresponding to the $1,2, \cdots, m$ principal component. The variance 
of $y_{1}, y_{2} \cdots y_{m}$ accounts for more than $90 \%$ of the total variance and basically reserved information of original factors $\left(x_{1}, x_{2}, \cdots, x_{p}\right)$ and the number of factors is decreased from $P$ to $m$, sifting factors.

\subsection{Application of the Method}

\subsubsection{Characteristic Parameter Extraction}

The key to log identification of diagenetic facies is parameters extracted from logging curves to reflect the characteristics of diagenetic facies. First, homing of depth of thin sections is achieved based on the contrast of the core natural gamma and the natural gamma curve with combination of core description. Diagenetic facies of 158 thin sections of 3 coring wells are named and sample layer data are extracted. Select 7 curves, i.e. GR, Rt, Rxo, CNL, DEN, AC and SP. The log response characteristics of sample layers corresponding to different diagenetic facies are shown in Table 2.

\subsubsection{Quantitative Log Recognition of Diagenetic Facies}

Prior to the principal component analysis of sample data, standardization must be done to eliminate the difference of dimension and order of magnitude of parameters to avoid the system error of calculation results. Dimension and order of magnitude of sample data is in the same range, and then the correlation coefficient matrix is calculated based on the standardized data. Get the eigenvalue $\lambda_{i}$ in the Jacobi method with the obtained correlation coefficient matrix $R$ of sample data and corresponding unit feature vector and variance contribution (Table 3).

The equation of principal component transform of tight sandstone reservoir of $\mathrm{Es}_{3} \mathrm{X}^{1}$ in block Zhuang 62-66 can be obtained from the feature vector corresponding to each eigenvalue:

$$
F_{1}=-0.45 R t+0.39 R x o-0.41 G R+0.5 A C
$$$$
-0.39 C N L-11.7 D E N+0.28 S P
$$

Table 2. Log response characteristics of different diagenetic facies of tight sandstone reservoir of $\mathrm{Es}_{3} \mathrm{x}^{1}$ in block $\mathrm{Zhuang}^{62-66}$.

\begin{tabular}{|c|c|c|c|c|c|c|c|}
\hline \multirow{2}{*}{ Diagenetic facies } & GR & $\mathbf{R t}$ & Rxo & CNL & DEN & $\mathbf{A C}$ & SP \\
\hline & $\mathbf{A P I}$ & $\mathbf{\Omega} \cdot \mathbf{m}$ & $\mathbf{\Omega} \cdot \mathbf{m}$ & $\%$ & $\mathrm{~g} / \mathrm{cm}^{3}$ & $\mathbf{u s} / \mathbf{f t}$ & $\mathbf{m V}$ \\
\hline Compaction-matrix filling and tightness & 98.2 & 9.2 & 7.2 & 18.7 & 2.52 & 82.3 & 72.3 \\
\hline Carbonate cementation and tightness & 61.1 & 53.4 & 51.9 & 5.4 & 2.48 & 59.2 & 65.4 \\
\hline Compaction-matrix filling and tightness & 72.2 & 7.3 & 5.8 & 15.3 & 2.39 & 82.1 & 63.5 \\
\hline Authigenic clay minerals filling and cementation & 95.6 & 8.4 & 8.2 & 15.4 & 2.46 & 84.6 & 45.3 \\
\hline Quartz overgrowth & 115.6 & 16.6 & 15.6 & 16.2 & 2.52 & 82.6 & 68.2 \\
\hline Authigenic clay minerals filling and cementation & 82.9 & 4.5 & 4.7 & 13.4 & 2.38 & 73.2 & 32.8 \\
\hline Unstable components dissolution & 80.1 & 8.2 & 6.5 & 16.1 & 2.4 & 76.8 & 46.2 \\
\hline Carbonate cementation and tightness & 72.5 & 62.2 & 60.8 & 12.5 & 2.62 & 70.4 & 80.2 \\
\hline Quartz overgrowth & 90.4 & 13.8 & 11.9 & 12.3 & 2.45 & 71.3 & 62.3 \\
\hline Unstable components dissolution & 93.2 & 18.7 & 15.8 & 23.6 & 2.43 & 86.3 & 60.3 \\
\hline Quartz overgrowth & 76.7 & 6.2 & 6.5 & 8.6 & 2.39 & 64.5 & 36.5 \\
\hline Carbonate cementation and tightness & 64.9 & 58.6 & 56.7 & 7.2 & 2.56 & 62.4 & 76.2 \\
\hline Authigenic clay minerals filling and cementation & 120.2 & 11.9 & 10.9 & 22.3 & 2.59 & 93.5 & 69.1 \\
\hline Unstable components dissolution & 72.9 & 5.4 & 4.1 & 12.7 & 2.32 & 70.3 & 40.2 \\
\hline Compaction-matrix filling and tightness & 118.4 & 13.6 & 14.3 & 26.4 & 2.6 & 89.3 & 80.2 \\
\hline
\end{tabular}

Table 3. Unit feature vectors, eigenvalues and variance contribution corresponding to eigenvalues.

\begin{tabular}{|c|c|c|c|c|c|c|c|c|c|}
\hline Feature vector & Eigenvalue & $a_{1}$ & $a_{2}$ & $a_{3}$ & $a_{4}$ & $a_{5}$ & $a_{6}$ & $a_{7}$ & $\begin{array}{c}\text { Variance contribution } \\
\text { /\% }\end{array}$ \\
\hline \hline$F_{1}$ & 2.68 & -0.45 & 0.39 & -0.41 & 0.5 & -0.39 & -11.7 & 0.28 & 53.6 \\
\hline$F_{2}$ & 1.89 & 0.32 & 0.98 & -0.24 & 0.57 & 0.23 & -0.63 & -0.78 & 37.8 \\
\hline$F_{3}$ & 0.31 & -0.16 & 0.32 & -0.65 & 0.28 & -0.44 & -8.7 & 0.57 & 6.2 \\
\hline$F_{4}$ & 0.12 & 0.98 & 1.56 & -0.09 & 0.83 & 0.56 & -3.4 & -0.64 & -2.3 \\
\hline$F_{5}$ & 0.05 & 0.8 & 0.67 & -0.39 & 1.63 & 0.9 & -2.4 & -8.7 & 0.1 \\
\hline
\end{tabular}




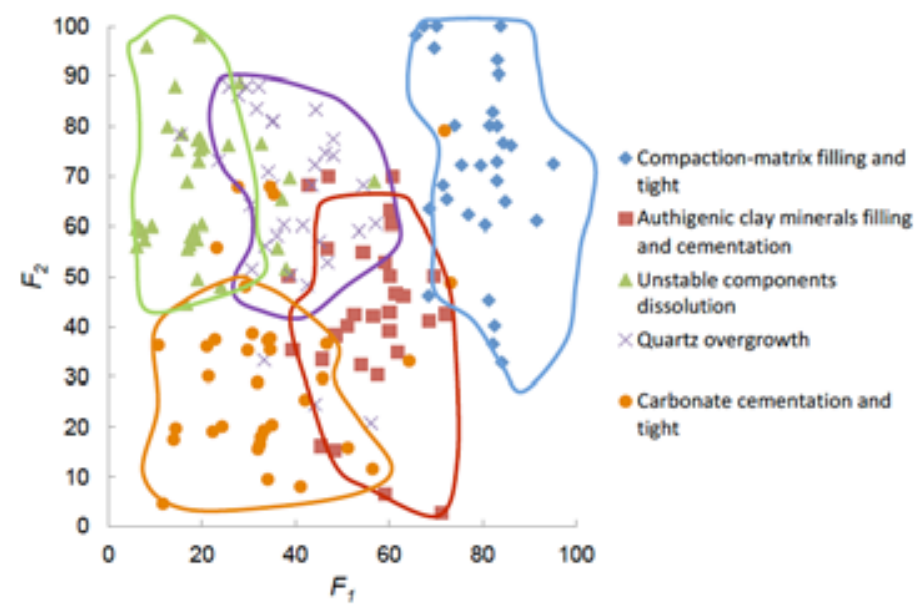

Fig. (2). Diagenetic facies recognition with the cross plot of principal components.

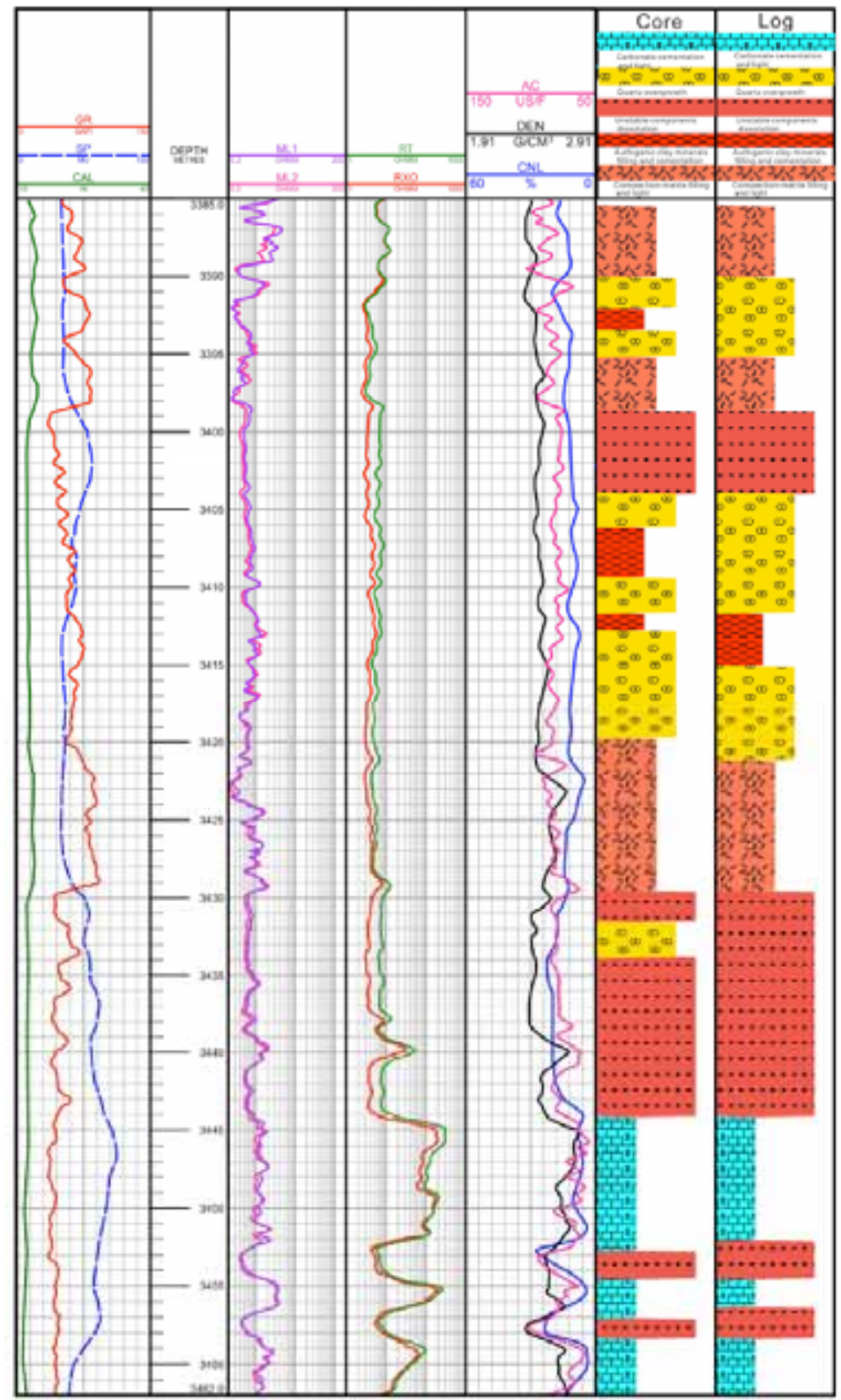

Fig. (3). Single well diagenetic facies recognition of tight sandstone reservoir of $\mathrm{Es}_{3} \mathrm{x}^{1}$ in block Zhuang 62-66. 
$F_{2}=0.32 R t+0.98 R x o-0.24 G R+0.57 A C$

$+0.23 C N L-0.63 D E N-0.78 S P$

$F_{3}=-0.16 R t+0.32 R x o-0.65 G R+0.28 A C$

$-0.44 C N L-8.7 D E N+0.57 S P$

$F_{4}=0.98 R t+1.56 R x o-0.09 G R+0.83 A C$

$+0.56 C N L-3.4 D E N-0.64 S P$

$F_{5}=0.8 R t+0.67 R x o-0.39 G R+1.63 A C$

$+0.9 C N L-2.4 D E N-0.87 S P$

Five calculation formulas of principal components can be obtained from the above formula, of which variance contribution of $F_{1}$ is the maximum, accounting for $53.6 \%$ of the total variance, while that of $F_{2}$ is $37.8 \% . F_{1}$ and $F_{2}$ account for $91.4 \%$ of the total variance, indicating they can replace the original seven logs with small loss of effective data information. According to the principal component transformation model, principal component calculation of 198 thin section identification samples of the study area is calculated. Cross plot analysis of diagenetic facies with the most important principal components $F_{1}$ and $F_{2}$ has been done (Fig. (2)), according to the cross plot, 5 diagenetic facies can be effectively distinguished, qualification rate of correction of core samples is up to $86.4 \%$ through analysis of actual data of well Z66-1 in the study area (Fig. (3)).

\section{CONCLUSION}

(1) Based on the research of $\log$ response mechanism of diagenesis and according to the "core calibrating log" criteria, principal component analysis is employed to integrate a variety of logging information to principal component variables for highlighting characteristics of diagenetic facies, and continuously quantitative recognition of diagenetic facies of reservoir of $\mathrm{Es}_{3} \mathrm{x}^{1}$ in block Zhuang 62-66 is achieved. Compared with lab analysis results, coincidence rate is as high as $86.4 \%$, verify the reliability of this method.

(2) Comprehensive analysis shows that selecting principal component variables to do crossplot whose cumulative variance contribution rate is greater than $90 \%$ could identify the diagenetic facies of reservior accurately, and solve the problem that direct use of logging crossplot variables could not identify diagenetic facies effectively.

\section{CONFLICT OF INTEREST}

The authors confirm that this article content has no conflict of interest.

\section{ACKNOWLEDGEMENTS}

This work is sponsored by the Chinese National Science and Technology Major Project (No.2011ZX05009-003).

\section{REFERENCES}

[1] J.L. Zhang, X.Q. Si, J. Liang and J. Liang, "Diagenesis of lacustrine deltaic sandstones and its impact on reservior quality", Acta Sedimentologica Sinica, vol. 22, no. 2, pp. 225-233, 2004.
[2] Y.Z. Wang, Y.C. Cao, S.Y. Chen, P. Wang and S.P. Wang, "Clastic reserviors characteristics and its control of mesozoic in Jiyang depression", Journal of China University of Petroleum (Edition of Natural Science), vol. 31, no. 5, pp. 7-11, 2007.

[3] F. Wang, J.C. Tian, R. Chen, M.R. Li and L. Xiao, "Analysis on controlling factors and characteristics of sandstone reservior of $\mathrm{He}$ 8 (Upper Paleozoic) in the Northern Ordos Basin”, Acta Sedimentologica Sinica, vol. 27, no. 2, pp. 238-245, 2009.

[4] D.Y. Li, J.L. Zhang, X.D. Jiang, and Z.Q. Jiang, "Diagenesis and its effect on Dainan sandstone reservior in Zhenwu-Caozhuang region of southern slope of Gaoyou depression", Earth Science: Journal of China University of Geosciences, vol. 38, no. 1, pp. 130142, 2013.

[5] S.P. Dutton and R.D. Loucks, "Diagenetic controls on evolution of porosity and permeability in Lower Tertiary Wilcox sandstones from shallow to ultradeep (200-6700m) burial, Gulf of Mexico Basin,USA", Marine and Petroleum Geology, vol. 27, no. 1, pp. 69$81,2010$.

[6] J.Q. Liu, X.Y. Lai, B.S. Yu, X.L. Chen and C. Sui, "The current situation and developing tendency of the study on diagenesis", $P e$ troleum Geology \& Experiment, vol. 28, no. 1, pp. 65-72, 2006.

[7] C.N. Zou, S.Z. Tao, H. Zhou, X.X. Zhang, D.B. He, C.M. Zhou, L. Wang, X.S. Wang, F.H. Li, R.K. Zhu, P. Luo, X.J. Yuan, C.C. Xu, and H. Yang, "Genesis,classification and evaluation method of diagenetic facies", Petroleum Exploration And Development, vol. 35, no. 5, pp. 526-540, 2008.

[8] L. Xu, X.H. Yu, Y. Yang, S.L. Li, Q.Q. Tian and Y. Zhou, "Diagenesis and diagenetic facies of tight sandstone reserviors in the $8^{\text {th }}$ member of the Shihezi Formation, southern Sulige Gas Field", Natural Gas Industry, vol. 32, no. 7, pp. 15-20, 2012.

[9] J. Lai, G.W. Wang, S.N. Wang, Y.Q. Zheng, H. Wu and Y.C. Zhang, "Research ststus and advances in the diagenetic facies of clastic reserviors", Adcances in Earth Science, vol. 28, no. 1, pp. 39-50, 2013.

[10] J.C. Shi, W. Sun, D.G. Lu, C.F. Li, Y.X. Lian and D.Z. Ren, "Diagenesis and diagenetic facies of Yanchang formation Chang- $8_{1}$ reservior in Baibao Area”, Geological Science and Technology Information, vol. 32, no. 4, pp. 31-37, 2013.

[11] H.Y. Ma, L.F. Zhou, X.G. Zhang, T.Y. Han, J.H. Li and G.L. Liu, "Diagenesis and favorable diagenetic facies of chang8 reservioe in Jiyuan area of Ordos Basin", Petroleum Geology \& Experiment, vol. 35, no. 4, pp. 378-384, 2013.

[12] J.L. Luo and Y.H. Li, "The dagenetic impact on reservior quality evolution of fluvial-deltaic sanstones - taking an example from the Upper Triassic sandstones of Chang 2 formation in the Yanchang oil field", Acta Sedimentologica Sinica, vol. 19, no. 4, pp. 541-547, 2001.

[13] K.M. Gould, D.J. Piper, G.P. Piper and R.A. MacRae, "Facies, provenance and paleoclimate interpretation using spectral gamma logs: Application to the Lower Cretaceous of the Scotian Basin", Marine and Petroleum Geology, vol. 57, pp. 445-454, 2014.

[14] W. Yang, G.Q. Wei, H. Jin, L. Zhang, Y.H. Shen and S.X. Wu, "Diagenesis and pore evolution of the oolitic shoal reservoir in the Feixianguan Formation in northeastern Sichuan", Geology In China, vol. 34, no. 5, pp. 822-828, 2007.

[15] Z.Q. Song, C.J. Tang, X.J. Liu, Z.Y. Pang and R.F. Wang, "Determination of favorable oil-bearing areas with extra lowpermeability reservior by "dessert" of petro-physical facies", Acta Petrolei Sinica, vol. 29, no. 5, pp. 711-716, 2008.

[16] Z.G. Cheng, Z.Q. Song, C. Jing, Y.F. He, L. Zhang and Q. Duan, "Tight gas reservior diagenetic facies classification and log responses in east Sulige area", Well Logging Technology, vol. 37, no. 2 , pp. 154-161, 2013.

[17] H.T. Zhang, Z. Shi, Y.J. Shi, L.L. Wang and L.J. He, "Diagenetic facies types and logging identification methods for lowpermeabilitytight sandstone reservoirs:a case study on the 8th member of XiashiheziFormation in Sulige gasfield, Ordos Basin”, Oil \& Gas Geology, vol. 33, no. 2, pp. 256-264, 2012.

[18] J. Lai, G.W. Wang, S.N. Wang, Y. Xin, Q.K. Wu, Y.Q. Zheng, J.L. $\mathrm{Li}$ and $\mathrm{D}$. Cang, "Overview and research progress in logging recongnition method of clastic reservior diagenetic facies", Journal of Central South University (Science and Technology), vol. 44, no. 12, pp. 4942-4953, 2013.

[19] G.Y Pang, J. Tang, Q. Wang, X.F. Ma and P. Liao, "Prediction of diagenetic facies with probabilistic neural network - taking member 
Chang 8 of Heshui Area in Ordos Basin as an example”, Special Oil \& Gas Reserviors, vol. 20, no. 2, pp. 43-47, 2013.

[20] Y. Bai, L.F. Xue,Y.J. Shi, B.Z. Pan, H.T. Zhang and J.Q. Wang, "An automatic identification method of log diagenetic facies and its application in Sulige area,Ordos Basin", Journal of China University of Petroleum(Edition of Natural Science), vol. 37, no. 1, pp. 35-41, 2013.

[21] D. Li, C.M. Dong, C.Y. Lin, L.H. Ren, T. Jiang and Z.X. Tang, "Control factors on tight sandstone reservoirs below source rocks in the Rangzijing slope zone of southern Songliao Basin, East China”, Petroleum Exploration And Development, vol. 40, no. 6, pp. 692-700, 2013.
Z. Wen, S.H. Yong and Z.W. Wang, "Quantitative discrimination of sedimentary microfacies by using well log data", Acta Sedimentologica Sinica, vol. 14, no. 1, pp. 40-46, 1996.

[23] J. Yu and G.H. Chen, "High-resolution sequence stratigraphic analysis with logging data", Well Logging Technology, vol. 31, no. 1, pp. 21-24, 2007.

[24] A.J. Liu, L. Zuo, J.J Li, R. Li, and W. Zhang, "Application of principal component analysis in carbonate lithology identification: a case study of the Cambrian carbonate reservoir in YH field", Oil \& Gas Geology, vol. 34, no. 2, pp. 192-196, 2013.

(C) Peng et al.; Licensee Bentham Open.

This is an open access article licensed under the terms of the Creative Commons Attribution Non-Commercial License (http://creativecommons.org/licenses/by-nc/3.0/) which permits unrestricted, non-commercial use, distribution and reproduction in any medium, provided the work is properly cited. 